Subscriber access provided by King Abdullah University of Science and Technology Library

Article

\title{
Porous-Hybrid Polymers as Platforms for Heterogeneous Photochemical Catalysis
}

Rana R. Haikal, Xia Wang, Youssef S. Hassan, Manas R Parida, Banavoth Murali, Omar F. Mohammed, Perry J. Pellechia, Marc Fontecave, and Mohamed H. Alkordi

ACS Appl. Mater. Interfaces, Just Accepted Manuscript • DOI: 10.1021/acsami.6b05031 • Publication Date (Web): 18 Jul 2016

Downloaded from http://pubs.acs.org on July 24, 2016

\section{Just Accepted}

"Just Accepted" manuscripts have been peer-reviewed and accepted for publication. They are posted online prior to technical editing, formatting for publication and author proofing. The American Chemical Society provides "Just Accepted" as a free service to the research community to expedite the dissemination of scientific material as soon as possible after acceptance. "Just Accepted" manuscripts appear in full in PDF format accompanied by an HTML abstract. "Just Accepted" manuscripts have been fully peer reviewed, but should not be considered the official version of record. They are accessible to all readers and citable by the Digital Object Identifier (DOI®). "Just Accepted" is an optional service offered to authors. Therefore, the "Just Accepted" Web site may not include all articles that will be published in the journal. After a manuscript is technically edited and formatted, it will be removed from the "Just Accepted" Web site and published as an ASAP article. Note that technical editing may introduce minor changes to the manuscript text and/or graphics which could affect content, and all legal disclaimers and ethical guidelines that apply to the journal pertain. ACS cannot be held responsible for errors or consequences arising from the use of information contained in these "Just Accepted" manuscripts. 


\title{
Porous-Hybrid Polymers as Platforms for Heterogeneous Photochemical Catalysis
}

\author{
Rana R. Haikal, ${ }^{\mathrm{a} \dagger}$ Xia Wang, ${ }^{\mathrm{b} \dagger}$ Youssef S. Hassan, ${ }^{\mathrm{a}}$ Manas R. Parida, ${ }^{\mathrm{c}}$ Banavoth Murali, ${ }^{\mathrm{c}}$ Omar F. \\ Mohammed, ${ }^{\mathrm{c}}$ Perry J. Pellechia, ${ }^{\mathrm{d}}$ Marc Fontecave ${ }^{\mathrm{b}}$ and Mohamed H. Alkordi $*^{\mathrm{a}}$ \\ ${ }^{a}$ Center for Materials Science, Zewail City of Science and Technology, Sheikh Zayed Dist., 12588, Giza, Egypt. \\ ${ }^{\mathrm{b}}$ Laboratoire de Chimie des Processus Biologiques, PSL Research University, Collège de France, CNRS UMR8229, Univer- \\ sité Pierre et Marie Curie,11 Place Marcelin Berthelot, 75231 Paris Cedex 05, France. \\ ${ }^{\mathrm{c}}$ Division of Physical Science and Engineering, Solar and Photovoltaics Engineering Research Center, King Abdullah Uni- \\ versity of Science and Technology (KAUST), Thuwal 23955-6900, Kingdom of Saudi Arabia. \\ ${ }^{\mathrm{d}}$ Department of Chemistry and Biochemistry, University of South Carolina, Columbia, South Carolina 29208, USA. \\ * Corresponding author: malkordi@zewailcity.edu.eg \\ these authors contributed equally
}

Abstract A number of permanently porous polymers containing Ru(bpy) photosensitizer or a cobaloxime complex, as a protonreduction catalyst, were constructed via one-pot Sonogashira-Hagihara (SH) cross-coupling reactions. This process required minimal workup to access porous platforms with control over the apparent surface area, pore volume, and chemical functionality from suitable molecular building blocks (MBBs) containing the Ru or Co complexes, as rigid and multi-topic nodes. The cobaloxime molecular building block, generated through in situ metalation, afforded a microporous solid that demonstrated noticeable catalytic activity towards hydrogen-evolution reaction (HER) with remarkable recyclability. We further demonstrated, in two cases, the ability to affect the excited state lifetime of the covalently-immobilized Ru(bpy $)_{3}$ complex attained through deliberate utilization of the organic linkers of variable dimensions. Overall, this approach facilitates construction of tunable porous solids, with hybrid composition and pronounced chemical and physical stability, based on the well-known $\mathrm{Ru}(\mathrm{bpy})_{\mathrm{n}}$ or the cobaloxime complexes.

Key words: porous-organic polymers, Ru complexes, photochemical heterogeneous catalysis, solid-state NMR, hydrogen evolving cobaloxime catalysts.

\section{Introduction}

Current and future global energy demands necessitate innovations to tap most available energy resources effectively and responsibly. ${ }^{1-2}$ In creating such innovations, scientists are actively exploring new technologies to design and develop new materials for harvesting solar energy. Despite the extensive efforts devoted to accomplish this goal, utilizing solar energy efficiently and cost-competitively has yet to be realized. $^{3-5}$. In addition to photoelectrical applications of Ru dyes ${ }^{6-}$ ${ }^{8}$, Ru and Co complexes have desirable photocatalytic properties for photochemical energy conversion applications, primarily for photocatalytic water splitting. ${ }^{9-10}$ Of particular interest are heterogeneous photocatalysts that can easily be separated and recycled from a reaction mixture. ${ }^{11-13}$

In efforts to address certain demanding applications, like gas storage and separation, $\mathrm{CO}_{2}$ capture, catalysis, and energy conversion, a large number of porous solids, namely metalorganic frameworks (MOFs), ${ }^{14}$ conjugated microporous polymers (CMPs) ${ }^{15}$ porous cross-linked polymers (PCPs), ${ }^{16-17}$ and porous-organic polymers (POPs), ${ }^{18}$ are being actively investigated. Porous solids, in general, are amenable to the bottom-up assembly from judiciously designed molecular building blocks (MBBs). POPs are an emerging class of polymeric materials accessible through covalent linkage of pre-selected MBBs.
POPs commonly exhibit rigid structures, high thermal and chemical stabilities, low densities, and in certain cases permanent porosity with specific surface areas surpassing those of well-known zeolites and porous silicates. ${ }^{19-21}$ Recent reports outlined several synthetic pathways to construct POPs including the Sonogashira-Hagihara $(\mathrm{SH})$ cross-coupling reaction. ${ }^{22}$ This approach, as being further exploited here, opens the door for utilization of a wider range of functional MBBs, namely brominated aromatic moieties, as compared with previous systems reported by Lin and co-workers that demonstrated photocatalytic activity of PCPs constructed through cobaltcatalyzed alkyne trimerization reaction. ${ }^{16-17}$ Our approach allowed the simultaneous incorporation of different building blocks into the solids backbone by including different brominated aromatic building blocks in the one-pot synthesis reported herein. Moreover, the multi-topic nature of the brominated $\mathrm{Ru}$ or Co complexes (up to 6 and 4 extension points, respectively) utilized in this study resulted in enhanced microporosity of the solids, in contrast to previous systems utilizing lower connectivity of the building blocks and consequently resulting in nonporous solids. ${ }^{17}$

In order to generate artificial photosynthesis systems, several attempts were made to mimic the energy transfer processes of photo-generated excitons in naturally occurring photosystems. ${ }^{23-26}$ 
A platform material that is amenable to rational design is thus of significance, facilitating optimization of intermolecular interactions towards applications in photochemical catalysis. Furthermore, a porous solid platform offers the potential for stability against several catalyst degradation processes, including leaching out of the support and/or self-induced degradation. ${ }^{18,27}$ The broad range of chemistry that can be implemented to fine tune certain platform materials includes (i) the degree of conjugation, length, connectivity, and functionality of the linkers, (ii) the various types of chromophores (iii) the large number of derivatives available for each chromophore, and (iv) the possibility of introducing heterogeneity into the structures by utilizing mixed chromophores. A number of MOFs based on certain chromophores have been recently reported and their photocatalytic behavior explored. ${ }^{25,28-30}$ Such solids with crystalline structures rely on coordination bonds between functional organic molecules, as linkers, and metal ions/clusters, as nodes, to sustain their structure. This very nature of MOFs can cause electronic isolation of the chromophores as well as, in some cases, chemical instability in certain environments, like moisture, acidic, or alkaline solutions, due to the reversible nature of the coordination bond. Our focus here is directed towards porous platform solids constructed through covalent linkage of designed multitopic chromophore, namely the Ru-polypyridyl photosensitizer, ${ }^{31}$ linked through proper organic linkers to generate a family of five porous, ruthenium-based, polymers (PRP 1-5). A structuredependence of excited state lifetime is demonstrated for two of the reported PRPs. Additionally, we investigated the potential to construct a porous, cobaloxime-based, polymer ( $\mathrm{PCoP}$ ) incorporating the known proton reduction catalyst, the cobaloxime. ${ }^{32}$ Finally, the catalytic performance of the PCoP was investigated and demonstrated remarkable catalytic behavior in terms of the turn-over-number in hydrogen evolving reaction, and recyclability under certain conditions.

\section{Results and Discussion}

In this report, we developed a one-pot synthesis strategy based on previously established SH cross-coupling pathways to construct porous organic polymers, ${ }^{53,54}$ where under carefully selected reaction conditions, ${ }^{33-34}$ porous polymers from bridging alkyne linkers and brominated Ru-polypyridyl or cobaloxime derivatives were successfully constructed, Scheme 1. In our approach, we expanded the realm of previously utilized cross-coupling reactions of rigid and directional molecular building blocks (MBBs) ${ }^{22,33-34}$ into more intricate ruthenium-based, and cobaloxime-based brominated metal complexes. This new approach afforded extended porous solids containing the Ru-polypyridyl or cobaloxime functionalities as integral parts of the polymers' backbone. Construction of porous solids from the aforementioned building blocks was accomplished under relatively mild reaction conditions that preserved the functionality and directionality of the building blocks. Indeed, five different compounds, PRPs 1-5, were isolated and characterized by several characterization techniques. Additionally, the cobaloxime-based polymer, PCoP, was synthesized then characterized similarly.

Due to the irreversible $\mathrm{C}-\mathrm{C}$ bond formation step, POPs constructed through cross-coupling reactions are widely amorphous solids insoluble in most common solvents. ${ }^{35}$ This aspect, while desirable for ease of separation and recyclability, however, precluded utilization of several solution or diffraction based structure characterization techniques. However, a wide range of structural characterization techniques including spectroscopic techniques like Fourier-transform infrared (FTIR), solid-state NMR, UV-Vis spectroscopy and energydispersive X-ray (EDX) spectroscopy were used to characterize the reported compounds. Other used characterization techniques including scanning electron microscopy (SEM), gas sorption, elemental analysis, and thermogravimetric analysis techniques, facilitated drawing a more detailed picture for the chemical composition of the obtained compounds. 

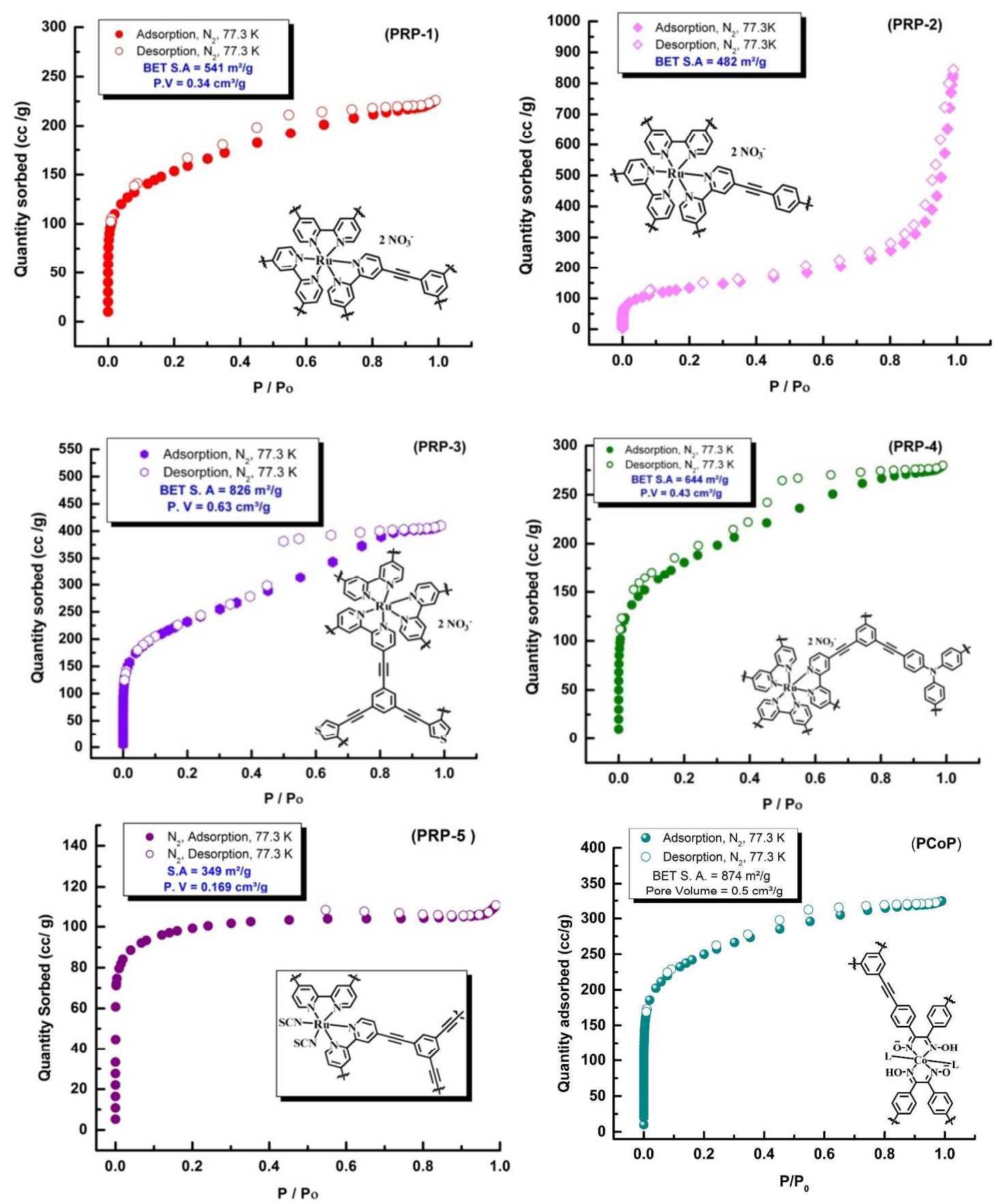

Figure 1. $\mathrm{N}_{2}$ gas sorption isotherms for the porous polymers PRP1-5 and for PCoP.

In particular, the reaction between tris-(4,4'-dibromo-2,2'dipyridyl) ruthenium (II) nitrate and 1,3,5-triethynyl benzene resulted in a deep-brown solid, PRP-1.The isolated solid was found to be insoluble in water and common organic solvents including DMF, DMSO, acetone, DCM, acetonitrile, $\mathrm{MeOH}$, and EtOH. Similar reaction conditions with different alkyne linkers and/or additional spacers were utilized to construct compounds PRP2-5 (please refer to Supporting Information, SI). The materials obtained were isolated by simple filtration and were subjected to solvent/guest exchange to remove resid- ual solvent and/or precursors. To extend our previous methodology into the realm of porous cobaloxime-containing polymers, in situ metalation of the 1,2-bis(4-bromophenyl)ethane1,2-dione dioxime by cobalt ions was first attempted (SI). When followed by addition of the terminal alkyne and proper catalyst, the targeted cobaloxime-based porous polymer was isolated as deep-brown solid, PCoP. $\mathrm{N}_{2}$ sorption isotherms for PRP 1-5 and PCoP were collected and are shown in Fig 1. The Brunauer-Emmett-Teller (BET) model applied to the $\mathrm{N}_{2}$ isotherm of the prototypal PRP-1 demonstrated a type I-like 
isotherm ${ }^{36}$ with calculated BET surface area of $541 \mathrm{~m}^{2} / \mathrm{g}$. Similar analysis of compounds PRP 2-5 indicated surface area values in the range of 348 to $826 \mathrm{~m}^{2} / \mathrm{g}$. In PRP-2, the ditopic 1,4-diethynylbenzene was used as the bridging alkyne linker. The observed reversible type II-like isotherm ${ }^{36}$ for PRP-2 could potentially indicate the presence of a mixed microporous/mesoporous pore system or alternatively can be attributed to gas condensation within the voids between sub micrometer agglomerates. ${ }^{37}$ This behavior could be ascribed to structural defects resulting from less than complete crosscoupling of the six-connected nodes through the linear ditopic alkyne linker. In compound PRP-3, the 3,4-dibromothiophene molecule was added to the reaction mixture to introduce the thiophene ring as a ditopic linker. Thiophene was selected due to its wide utilization as a molecular component in organic solar cells and molecular wires. Additionally, it appears that the directionality of the 3,4-dibromothiophene ring led to some backbone twist during formation of PRP-3, thus increasing its surface area as compared to PRP-1. In an additional example, the triphenylamine extended linker was used to construct PRP-4 which demonstrated increased surface area and pore volume as compared to PRP-1 $\left(644 \mathrm{~m}^{2} / \mathrm{g}, 0.43 \mathrm{~cm}^{3} / \mathrm{g}\right.$ for PRP-4 as compared to $541 \mathrm{~m}^{2} / \mathrm{g}, 0.34 \mathrm{~cm}^{3} / \mathrm{g}$ for PRP-1). In compound PRP-4, the triphenylamine MBB, utilized as an extended three-connected linker, was judiciously selected due to its wide utilization as an electron donor species (hall transport medium) in organic photovoltaic cells. The observed $\mathrm{N}_{2}$ sorption isotherm for PRP-3,4 can be classified as type IVlike character demonstrating H2-type hysteresis. ${ }^{37}$ This behavior is common among porous organic polymers and can be associated with swelling of the polymers rather than taken to indicate presence of mesoporosity inside the material. ${ }^{37}$ In PRP-5, the heteroleptic $\mathrm{Ru}(\mathrm{NCS})_{2}(\mathrm{bpy})_{2}$ coordination cluster was utilized for its known photoactivity, ${ }^{38}$ and resulted in a microporous polymer with fully reversible, type-I $\mathrm{N}_{2}$ sorption isotherm (BET surface area of $349 \mathrm{~m}^{2} / \mathrm{g}$ ). The pore size distribution in PRP-5 is remarkable as it indicates uniform and narrow distribution at ranges of 5, 10 and $15 \AA$ (SI). The reduced apparent surface area of PRP-5 relative to the rest of the reported compounds here can be attributed to the reduced number of extension points (four brominated aromatic carbons as compared to six in the earlier examples) from which polymer growth and inter-chain linkage commenced. The $\mathrm{N}_{2}$ sorption isotherm for PCoP , Fig. 1, demonstrated a type I-like character. For PCoP the calculated apparent BET surface area and total pore volume were found to be $874 \mathrm{~m}^{2} \mathrm{~g}^{-1}$, and $0.5 \mathrm{~cm}^{3} \mathrm{~g}^{-1}$, respectively.

The solid-state ${ }^{13} \mathrm{C}$-CPMAS-NMR spectra collected for PRPs 1-5, shown in Fig 2, clearly indicated the targeted assembly of molecular building blocks into extended networks. The observed ${ }^{13} \mathrm{C}$ chemical shifts include those for internal alkyne (80-90 ppm), aromatic carbons (120-140 ppm) and aromatic carbons $(\alpha)$ to the nitrogen atoms in the bpy rings (C6 and C2 expected at $\sim 150$ and $\sim 157$ ppm, respectively). ${ }^{39}$ Comparison between the relative ${ }^{13} \mathrm{C}$ peak intensities at the

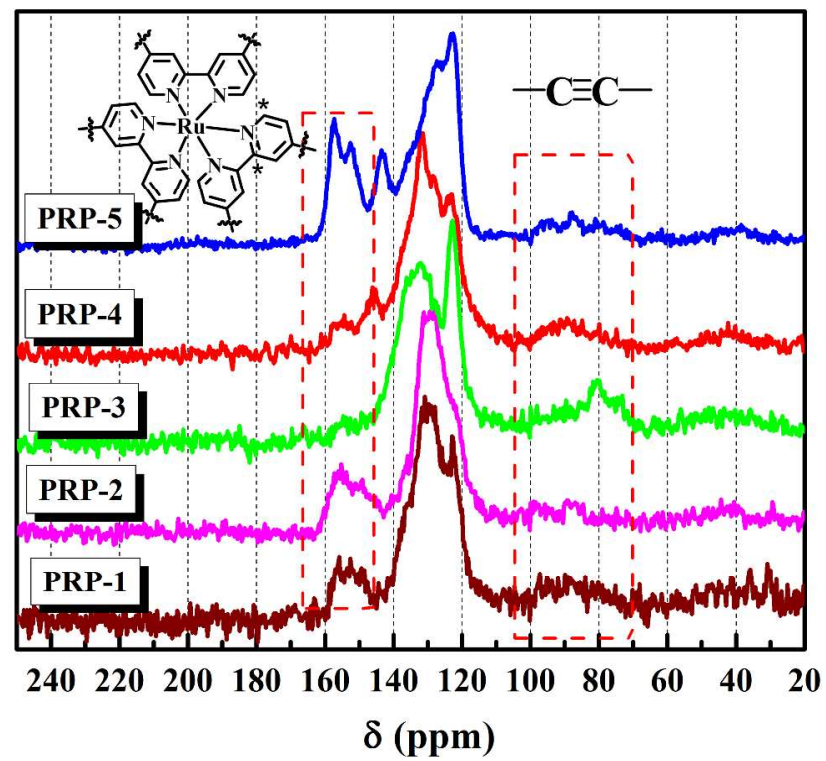

Figure 2. Stacked ${ }^{13} \mathrm{C}-\mathrm{CP}-\mathrm{MAS}$ NMR spectra of PRPs 1-5.

five PRPs indicates an increase in the ratio of aromatic, ${ }^{13} \mathrm{C}$ signals $(\sim 120 \mathrm{ppm})$ relative to the other ${ }^{13} \mathrm{C}$ signals moving from PRP-1 to PRP-4. This is in agreement with the expected increase in the number of aromatic secondary carbons per polymeric repeat unit from PRP-1 to PRP-4, further supporting the repeat unit structures proposed for the respective PRPs. The distinctly observed signal $(\sim 143 \mathrm{ppm})$ in the ${ }^{13} \mathrm{C}$-CPMAS NMR spectrum of PRP-5 falls within the range expected for isothiocyanate ions. This observation further supports the proposed structure of PRP-5, to contain Ru-coordinated isothiocyanate. The presence, if any, of unreacted brominated aromatic carbon atoms (expected chemical shift at $\sim 135 \mathrm{ppm}$ ) cannot be ascertained from the collected spectra due to masking by signals from other parts of the polymers. The ${ }^{13} \mathrm{C}$ CPMAS spectrum for PCoP is shown in the SI and demonstrated peaks at chemical shifts of $89.47 \mathrm{ppm}$ (attributed to the internal alkyne $s p$ carbon atoms) and at $129.7 \mathrm{ppm}$ (assigned to the aromatic carbons in the backbone). The broadness of the observed peaks indicated relatively heterogeneous texture of the material and can be ascribed to polymer length/connectivity polydispersity. No additional peaks were detected in the spectrum and the absence of other characteristic peaks could potentially be ascribed to broadening to the signal due to interactions with the Co center.

The successful assembly of the MBBs into PRPs 1-5 and in PCoP was also evidenced by attenuated total reflectance FTIR spectroscopy (SI). Linkage through alkyne groups was shown from the absence or the strong attenuation of the terminal alkyne $v_{\mathrm{C}-\mathrm{H}}$ stretching band (observed at $3272 \mathrm{~cm}^{-1}$ for 1,3,5-triethynylbenzene and at $3260 \mathrm{~cm}^{-1}$ for 1,4diethynylbenzene) and the detection of the $v_{\mathrm{C} \equiv \mathrm{C}}$ stretching band shifted towards higher wave numbers in the products as compared to reactants (From 2105 2112 $\mathrm{cm}^{-1}$ in starting alkynes to $2170 \sim 2200 \mathrm{~cm}^{-1}$ in the products). Additional infrared spectroscopic markers in the FTIR spectra of the isolated 

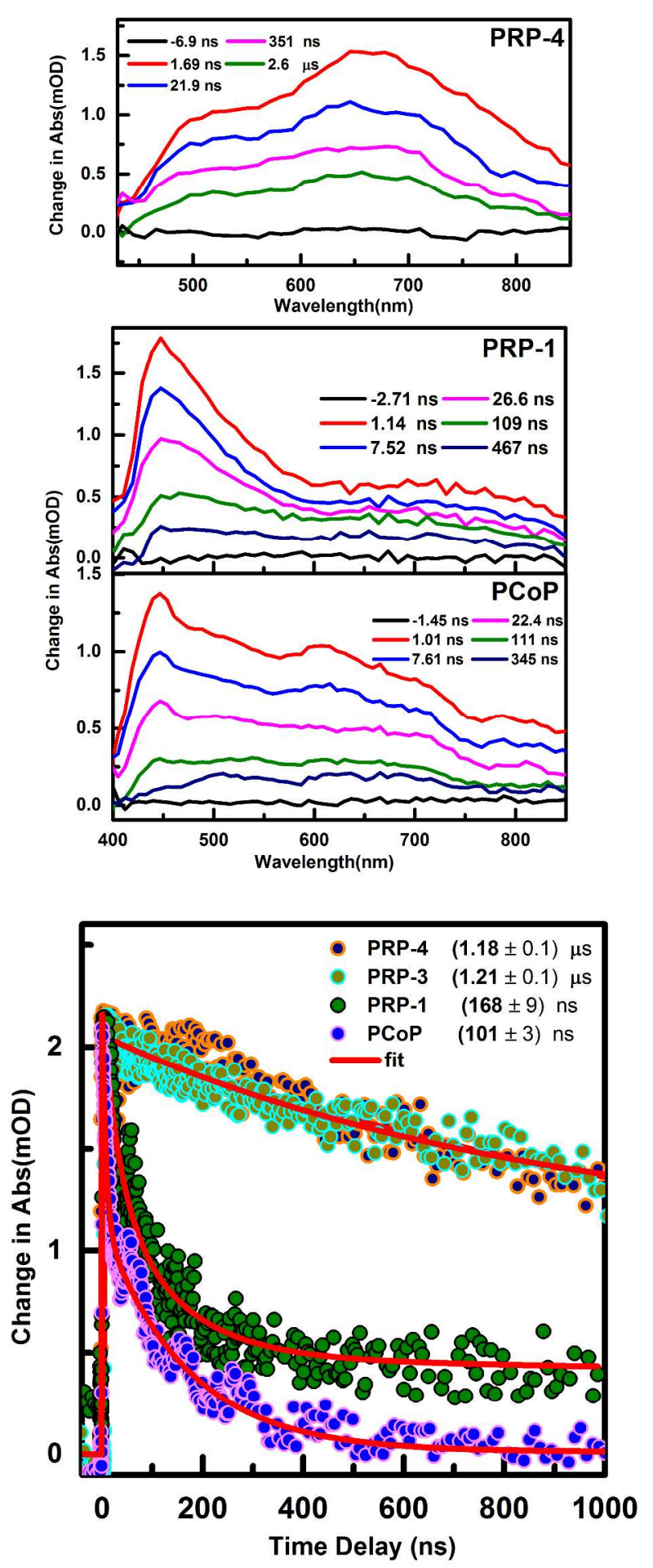

Figure 3.Transient absorption spectra for PRP-1,4 and PCoP and the triplet state decay curves for PRPs-1, 3, 4 and PCoP.

compounds included a nitrate stretching band at $\sim 820 \mathrm{~cm}^{-1}$ and bpy-centered bands, $v_{(\mathrm{C}-\mathrm{C} / \mathrm{C}-\mathrm{N})}$, at $1570 \sim 1600 \mathrm{~cm}^{-1}$ and $v_{(\mathrm{C}-\mathrm{C} / \mathrm{Ru}-\mathrm{N})}$ at $1480 \mathrm{~cm}^{-1} \cdot{ }^{40}$ Additionally, in PRP-5, a strong absorption band observed at $2094 \mathrm{~cm}^{-1}$ was assigned to the $v_{\mathrm{C}=\mathrm{N}}$ stretching of the isothiocyanate ion. For the PCoP, additional characteristic IR spectroscopic markers were observed, including broad $v_{\mathrm{O}-\mathrm{H}}$ stretching band centered at $3300 \mathrm{~cm}^{-1}$ and a $v_{\mathrm{C}=\mathrm{N}}$ stretch- ing band at $1670 \mathrm{~cm}^{-1}$, further supporting the incorporation of the oxime functionality into the isolated solid.

As time-resolved laser spectroscopy is an extremely powerful technique to probe the excited state deactivation pathways directly, we performed ultrafast pump-probe experiments with femtosecond and broadband capabilities to record the time-resolved, excitation-induced difference spectra. Detailed information about the experimental setup can be found elsewhere. ${ }^{41-42}$ The transient absorption and the excited state decay data for PRP-1,3,4, recorded following $340 \mathrm{~nm}$ optical excitation pulses, are shown in Fig. 3. As can be clearly seen, the triplet state lifetime of PRPs-3, $\mathbf{4}$ are almost seven times larger than that of PRP-1 $(1.21 \mu \mathrm{s}, 1.18 \mu \mathrm{s}$, and $168 \mathrm{~ns}$, respectively), indicating the dependence of the triplet-state lifetime on the backbone structure and hence microenvironment of the chromophore in the PRPs.

Indeed, the more widely spaced chromophores in PRPs3, 4 displayed prolonged excited-state lifetimes. One possible explanation for this observation is that enhanced excited state stabilization through solvation by enclathrated solvent molecules is more pronounced in PRPs-3, 4 with larger pore volumes and surface area values. Alternatively, enhanced geometrical separation of the chromophores, in PRPs-3, 4 as compared to PRP-1, could be responsible for the observed increase in the excited state lifetime. This is to be expected assuming certain relaxation pathways, like the Dexter tripletto-triplet energy transfer process, to be weaker in PRP-3, 4 with more spaced chromophores. It is worth pointing out that the triplet state lifetime values of our compounds, especially PRPs-3, $\mathbf{4}$ are much longer than triplet state lifetimes of other derivatives of the $\mathrm{Ru}$ photosensitizer that are commonly used in dye-sensitized solar cells. ${ }^{38,43}$ It is relevant here to mention recent reports on almost nonporous Ru-based conjugated polymers $(\mathrm{CPs})^{17,44}$ which demonstrated good photochemical catalytic activity. Efficient excited-state migration via Dexter triplet-to-triplet energy transfer among the chromophore framework was postulated in these polymers. ${ }^{29-31}$ Similarly, the excited-state lifetime of the PCoP was measured (101 ns) and was found to relax relatively quickly to its ground state.

To characterize the surface morphology of some of the constructed solids, field-emission (FE-SEM) images were obtained for PRP-1 and PCoP, Fig 4. The FE-SEM image of the PRP-1 revealed relatively smooth surface morphology indicative of small particle/grain size. The FE-SEM image of the PCoP revealed rough surface texture indicative of larger particle/grain size. Additionally, EDX color-coded elemental analysis maps were recorded for the aforementioned two solids, Fig 4. The EDX maps clearly indicated mostly carbon composition of the compounds analyzed, with noticeable presence of Ru in PRP-1 and Co in PCoP. Additionally, the EDX analysis for both solids indicated the presence of $\mathrm{Br}$, ascribed to polymer chain termination with brominated aromatic molecules, SI. 

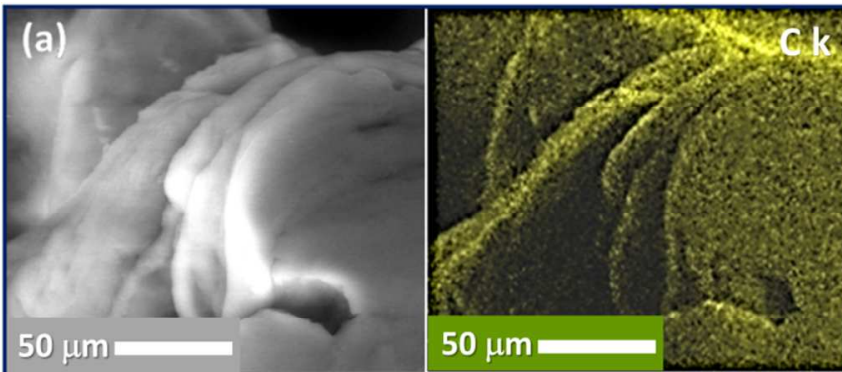
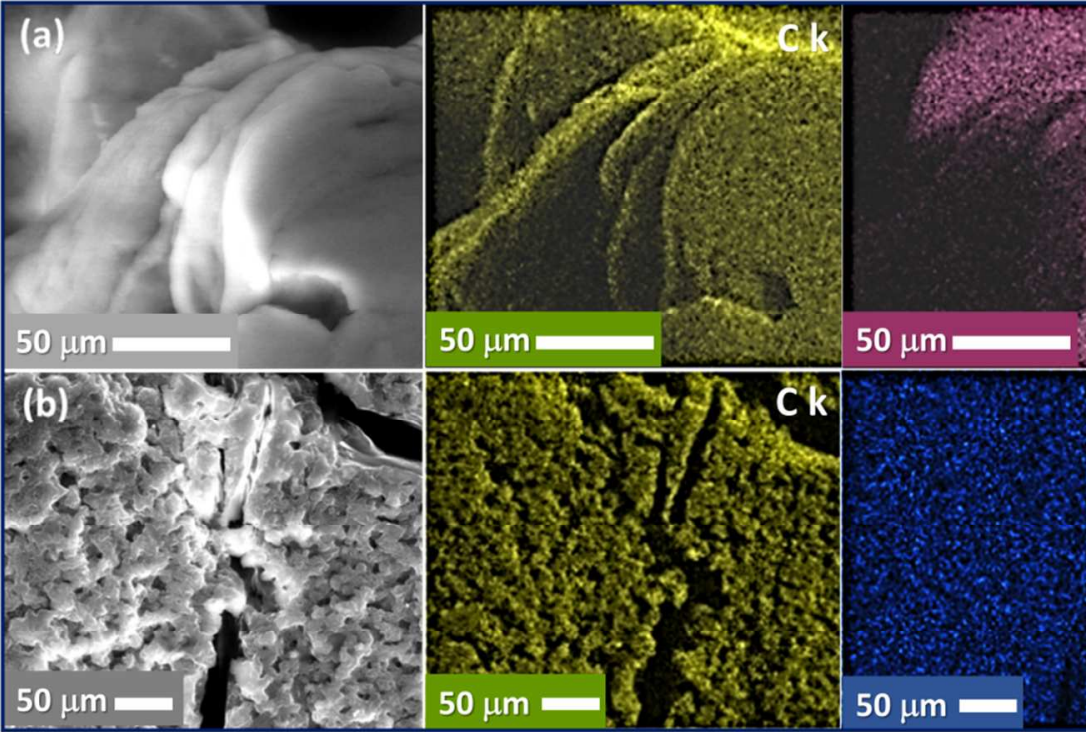
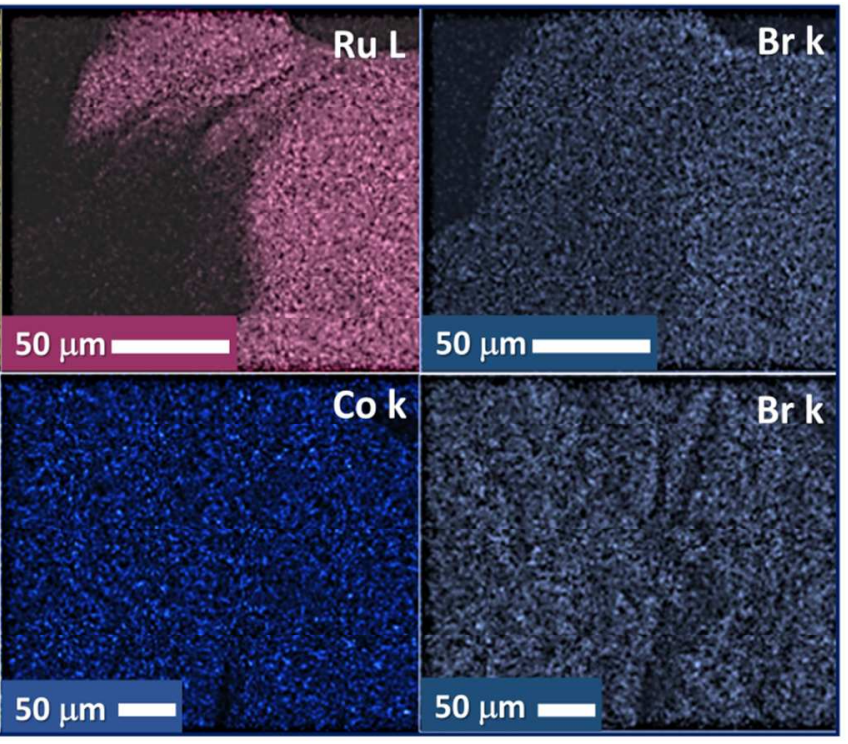

Figure 4. SEM images of PRP-1 (a) and the PCoP (b) and the corresponding color-coded EDX elemental analysis maps (labeled images).

The proton reduction photocatalytic activity of PCoP was studied under standard conditions using $\left[\mathrm{Ru}(\mathrm{bpy})_{3}\right] \mathrm{Cl}_{2}$ as a photosensitizer under visible-light irradiation $(\lambda>415 \mathrm{~nm})$ (table 1). In the first system, an organic solvent, acetonitrile $(\mathrm{ACN})$, was combined with triethanolamine (TEOA) acting both as a sacrificial electron donor and a proton donor, respectively $(5: 1, v / v)$. Under these conditions PCoP proved active, as $0.90 \mu \mathrm{mol} \mathrm{H}_{2} / \mathrm{mg}$ was produced after 5 hours irradiation (entry 1 in Table 1). Based on EDX analyses, our material was shown to contain $\sim 1.9 \pm 0.4 \mathrm{wt} \%$ cobalt, thus the activity translated in $2.8 \mathrm{TON}$ in 5 hours reaction time. If TEOA was replaced by triethylamine (TEA) (entry 2 in Table 1) or ascorbic acid (entry 3 in Table 1) in the presence of water as the proton donor, almost no catalytic activity could be observed in the same period of irradiation time. In the second system water under moderately acidic conditions $(\mathrm{pH} 3.0-5.0)$ was used as the solvent. Interestingly, when the catalyst PCoP was assayedin water containing $0.1 \mathrm{M}$ ascorbic acid (entry 4-8 in table 1), especially when the $\mathrm{pH}$ of the solution was at 4 and 4.5, an impressive $\mathrm{H}_{2}$ production $(10.17 \mu \mathrm{mol} / \mathrm{mg}, 32 \mathrm{TON}$, and $7.49 \mu \mathrm{mol} / \mathrm{mg}, 24 \mathrm{TON}$, respectively) was observed during 5 hours photolysis. This $\mathrm{pH}$-dependence is well known ${ }^{45}$ : indeed at too acidic $\mathrm{pH}$, the reducing power of ascorbic acid is weakened. At too basic $\mathrm{pH}$, catalysis is limited by the availability of protons in the system. In both solvent conditions, no $\mathrm{H}_{2}$ was detected in the absence of the catalyst PCoP, or the photosensitizer $\mathrm{Ru}(\mathrm{bpy})_{3} \mathrm{Cl}_{2}$, or when the reactions were undertaken in the dark. Under the optimal conditions, using 10 $\mathrm{mM}$ of the photosensitizer, a time curve was obtained for long term experiments, Fig. 5, showing a sustained production of $\mathrm{H}_{2}$. An initial rate of $0.14 \mu \mathrm{mol} \mathrm{H} / \mathrm{mg} / \mathrm{h}$ and 21 TONs after 62 hours were obtained using the ACN/TEOA system, while the water/ascorbate system was about 20 times more efficient, with an initial rate of $2.46 \mu \mathrm{mol} / \mathrm{mg} / \mathrm{h}$ and 62 TONs after 10 hours. However, the former proved much more photostable, as the
Table 1. Photocatalytic $\mathrm{H}_{2}$ production under different solvent systems $^{\text {a }}$

\begin{tabular}{|c|c|c|}
\hline Entry & Solvent system & $\begin{array}{l}\mathrm{H}_{2} \text { production } \\
\text { ( } \mu \mathrm{mol} / \mathrm{mg} \text { cat.) }\end{array}$ \\
\hline 1 & $\mathrm{ACN}^{\mathrm{T}} \mathrm{TEOA}{ }^{\mathrm{b}}$ & 0.90 \\
\hline 2 & $\mathrm{ACN} / \mathrm{H}_{2} \mathrm{O} / \mathrm{TEA}^{\mathrm{c}}$ & 0 \\
\hline 3 & $\mathrm{ACN} / \mathrm{H}_{2} \mathrm{O} /$ ascorbic acid, $\mathrm{pH} 4.0^{\mathrm{d}}$ & 0.02 \\
\hline 4 & $\mathrm{H}_{2} \mathrm{O} /$ ascorbic acid, $\mathrm{pH} 3.0^{\mathrm{e}}$ & 0 \\
\hline 5 & $\mathrm{H}_{2} \mathrm{O} /$ ascorbic acid, $\mathrm{pH} 3.5^{\mathrm{e}}$ & 1.43 \\
\hline 6 & $\mathrm{H}_{2} \mathrm{O} /$ ascorbic acid, $\mathrm{pH} 4.0^{\mathrm{e}}$ & 10.17 \\
\hline 7 & $\mathrm{H}_{2} \mathrm{O} /$ ascorbic acid, $\mathrm{pH} 4.5^{\mathrm{e}}$ & 7.49 \\
\hline 8 & $\mathrm{H}_{2} \mathrm{O} /$ ascorbic acid, pH 5.0 & 0 \\
\hline
\end{tabular}

${ }^{\text {a }}$ Photocatalytic $\mathrm{H}_{2}$ production in the presence of $\mathrm{PCoP}$ as a catalyst, $\mathrm{Ru}(\mathrm{bpy})_{3} \mathrm{Cl}_{2}$ as a photosensitizer, and a $415 \mathrm{~nm}$ cutoff filter.

${ }^{\mathrm{b}}$ Volumetric ratio of ACN/TEOA is $5: 1$

${ }^{c}$ Volumetric ratio of $\mathrm{ACN} / \mathrm{H}_{2} \mathrm{O} / \mathrm{TEA}$ is $4.5: 4.5: 1$

${ }^{\mathrm{d}}$ Volumetric ratio of $\mathrm{ACN} / \mathrm{H}_{2} \mathrm{O}$ is $1: 1,0.1 \mathrm{M}$ ascorbic acid, $\mathrm{pH}$ adjusted by $\mathrm{NaOH}$

${ }^{\mathrm{e}} 0.1 \mathrm{M}$ ascorbic acid, $\mathrm{pH}$ adjusted by $\mathrm{NaOH}$

PCoP under this condition could be recycled for at least 5 times (16 hours photolysis each run) with maintaining full activity, Fig.6a,. The retention of the activity of the solid catalyst after 5 days of cumulative photolysis time proves the impressively good photostability of PCoP in this system. In contrast in the water/ascorbate system, the catalyst lost more than half of its activity during the second run and was totally inactivated during the third one, Fig. $\mathbf{6 b}$. It is possible that the acidic condition of the system, while favoring proton reduction, affected the integrity of the catalyst, under irradiation. The stability of the PCoP-based system is remarkable. Recently heterogeneous coordination polymers and functionalized metal-organic frameworks (MOFs) have been reported to 


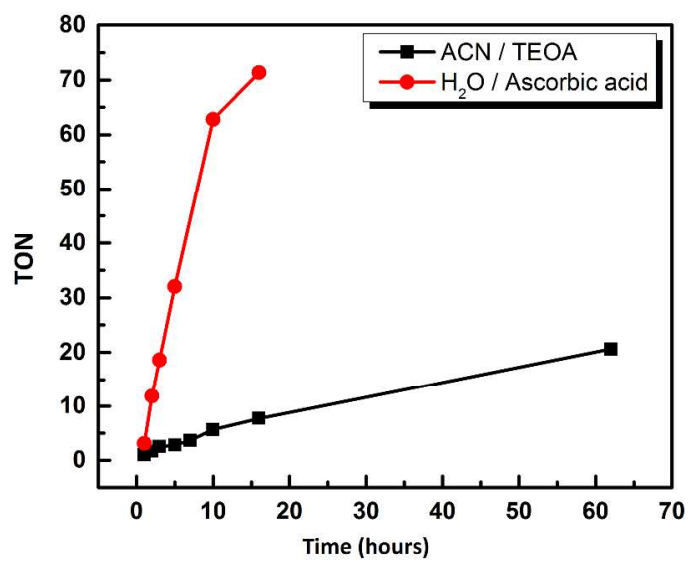

Figure 5. Catalytic activity for the $\mathrm{PCoP}$ towards $\mathrm{H}_{2}$ production in the two systems reported. Conditions: $\mathrm{Ru}(\text { bpy })_{3} \mathrm{Cl}_{2}(10 \mathrm{mM})$, filter $>415 \mathrm{~nm}$. Black squares: $\mathrm{H}_{2}$ evolution in a 5:1 (v:v) ACN/TEOA solvent system under $\mathrm{N}_{2}$ saturated conditions. Red circles: $\mathrm{H}_{2}$ evolution in an $\mathrm{H}_{2} \mathrm{O}$ /ascorbic acid $(0.1 \mathrm{M}) \mathrm{pH} 4$ solvent system under $\mathrm{N}_{2}$ saturated conditions.
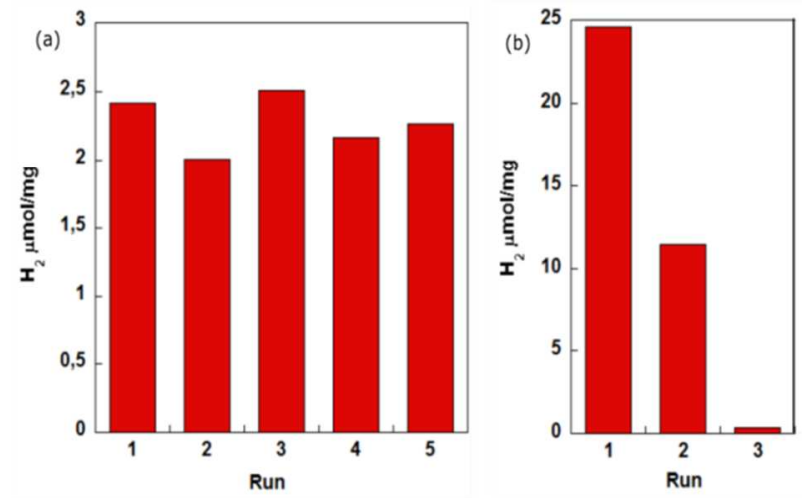

Figure 6. $\mathrm{H}_{2}$ production measured during recyclability experiments. (a) ACN/TEOA solvent system (runs of 16 hours photolysis each), (b) $\mathrm{H}_{2} \mathrm{O}$ /ascorbic acid $(0.1 \mathrm{M}) \mathrm{pH} 4$ solvent system (runs of 16 hours photolysis each).

function as catalysts for light-driven hydrogen generation, however in general with much less stability. For example, a $\mathrm{Cu}$ (II) coordination polymer was inactivated after 5 hours reaction. ${ }^{46}$ Incorporation within MOFs of dinuclear iron complexes mimicking the active site of hydrogenases gave catalysts for photocatalytic hydrogen generation. However, the reaction stopped after a very short reaction time $(<2$ hours $)$ due to catalyst deactivation. ${ }^{47-48}$ Finally, it is interesting to note that while molecular cobaloximes are good catalysts as well, they also suffer, within comparable photochemical conditions, from low stability, with full inactivation after a few hours. ${ }^{49-50}$ We also found that the cobaloxime precursor of PCoP was active using the ACN/TEOA system and $\mathrm{Ru}(\mathrm{bpy})_{3} \mathrm{Cl}_{2}$ as the photosensitizer under the conditions used with PCoP (SI).As the amount of Co was comparable to that provided by the PCoP catalyst, the data show that the free cobaloxime was slightly less efficient. Furthermore, it was found to be much less stable as $\mathrm{H}_{2}$ production stopped after about 10 hours reaction. It was recently demonstrated that stabilization of these homogeneous molecular catalysts can be obtained using axial
N-ligands such as imidazole derivatives. ${ }^{51}$ Such a strategy might also be used to further improving the PCoP catalyst. A recent report by Cooper and co-workers demonstrated photochemically-active family of linear, planarized conjugated polymers of fluorene, carbazole, dibenzo[b,d]thiophene and dibenzo- $[\mathrm{b}, \mathrm{d}]$ thiophene sulfone functionalities. The reported polymers were investigated for photochemical hydrogen evolution, where among the reported polymers the most active dibenzo[b,d]thiophene sulfone copolymer showed the most activity. ${ }^{52}$ Our PCoP performed with comparable TOF to most of the reported polymers by Cooper and Co-workers in terms of $\mu \mathrm{mol} \mathrm{H}_{2} / \mathrm{hr}$ produced for each mg of catalyst used, with the exception being the most two active polymers P6 and P7. As our PCoP catalyst is microporous with relatively large surface area, in contrast to the non-porous polymers studied in this recent report, there is a wide potential to tune and further enhance its catalytic activity through controlled diffusion of redox shuttles, electrolytes, and/or photosensitizers.

\section{CONCLUSION}

In conclusion, we describe, for the first time and to the best of our knowledge, an approach to constructing permanently porous polymers of the ruthenium-tris(2,2 -bipyridyl), $\mathrm{Ru}(\mathrm{bpy})_{3}$ and cobaloxime with large surface areas, variable backbone functionality and long-lived excited state lifetimes that can potentially be exploited for applications in heterogeneous photocatalysis. In addition, our approach utilizes onepot Sonogashira-Hagihara cross-coupling synthesis, with minimal workup through simple filtration and solvent/guest exchange, making it very appealing for large-scale production. Our results clearly indicate a lifetime dependence of the chromophores on the chemical nature of the backbone, and furthermore photocatalytic activity towards proton reduction and recyclability of the porous catalyst is explored.

\section{EXPERIMENTAL SECTION}

All air-sensitive manipulations were performed under a dry $\mathrm{N}_{2}$ atmosphere using standard Schlenk line techniques. Chemicals were purchased from Alfa-Aesar (triphenylphosphine, 1,3,5-triethynylbenzene, 1,4diethynylbenzene);

Sigma-Aldrich bis(triphenylphosphine)palladium(II) dichloride, silica gel, ethanol, THF,absolute ethanol); Fisher-UK (methanol,potassium nitrate, $\mathrm{RuCl}_{3}$, DMF, acetonitrile); CombiBlocks (4,4'-dibromo-2,2`-dipyridine), Acros Organics (CuI,); VWR(triethylamine Chromanorm ${ }^{\circledR}$, HPLC grade). All reagents were used as received without further purification. $\mathrm{Ni}$ trogen and $\mathrm{CO}_{2}$ gasses for sorption were purchased from AirLiquide $\left(\mathrm{N}_{2}\right.$ AlphaGaz2 (99.999\%) and $\left.\mathrm{CO}_{2}(99.995 \%)\right)$. Gas sorption analysis was performed on MicromereticsASAP2020 and the variable temperature $\mathrm{CO}_{2}$ isotherms were recorded in insulated dewar connected to LAUDA RA-8 circulating chiller. UV-Vis spectra were acquired on ThermoScientific Evolution600 UV-Vis spectrophotometer equipped with inte- 
grating sphere for solids. Infra-red absorption spectra were recorded on ThermoScientific Nicolet is-10. Thermogravimetric analyses were conducted on Thermal AnalysisQ50.Synthetic reactions were performed under nitrogen atmosphere in oven-dried glassware.

Tris(4,4'-dibromo-2,2'-bipyridine) ruthenium (II) nitrate: In a glass pressure vessel fitted with Teflon screw cap $(50 \mathrm{~mL})$ charged with a magnetic stirrer was added absolute ethanol $(40 \mathrm{~mL})$ and the solvent degassed through 3 cycles of freezepump-thaw and kept under nitrogen. To this degassed solvent was added 4,4'-dibromo-2,2'-bipyridine $(0.314 \mathrm{~g}, 1 \mathrm{mmol})$ and tetrakis-(dimethylsulfoxide) ruthenium(II) chloride $(0.154 \mathrm{~g}$, $0.32 \mathrm{mmol}$ ) and the vessel closed under nitrogen. The reaction mixture was maintained at $70^{\circ} \mathrm{C}$ for 24 hours (color changes to deep red-brown). The solution was then cooled to room temperature, filtered through a fritted funnel and the ethanol removed under reduced pressure. The crude solid was loaded on silica as acetonitrile solution then the silica dried under reduced pressure. The crude product loaded on silica was subjected to column chromatography on silica with a mobile phase consisting of saturated aqueous $\mathrm{K}\left(\mathrm{NO}_{3}\right)$ : water: acetonitrile $(1: 1: 20)$ and the second band was collected. Evaporation of the solvent gave a deep red solid $(0.194 \mathrm{~g}$, yield $60 \%$, based on a molecular formula weight of $\left.1167 \mathrm{~g} \mathrm{~mol}^{-1}\right)$. ESI/FT-MS: $\left[\mathrm{C}_{30} \mathrm{H}_{18} \mathrm{Br}_{6} \mathrm{~N}_{6} \mathrm{Ru}\right]^{2+}$ found 521.783252, calculated 521.783215.

\section{Synthesis of PRP-1}

In a glass pressure vessel fitted with Teflon screw cap (100 $\mathrm{mL})$ charged with a magnetic stirrer a mixture of DMF (15 $\mathrm{mL})$ and $\mathrm{Et}_{3} \mathrm{~N}(5 \mathrm{~mL})$ was prepared. The vessel was capped with silicon septum, and the solvent mixture was evacuated and backfilled with nitrogen three times through a needle, then was kept under nitrogen for $10 \mathrm{~min}$. To this mixture and under nitrogen atmosphere was added tris-(4,4'-dibromo-2,2'bipyridine) ruthenium (II) nitrate $(0.09 \mathrm{~g}, 0.077 \mathrm{mmol}), 1,3,5$ triethynylbenzene $(0.023 \mathrm{~g}, 0.155 \mathrm{mmol}, 2$ equiv. $)$, bis(triphenylphosphine)palladium(II) dichloride $(0.014 \mathrm{mmol}$, $10 \mathrm{mg})$, triphenylphosphine $(0.02 \mathrm{mmol}, 0.005 \mathrm{~g})$ and $\mathrm{CuI}$ $(0.025 \mathrm{mmol}, 0.005 \mathrm{~g})$, the flask was then evacuated/backfilled with nitrogen and sealed and the mixture was stirred at $80{ }^{\circ} \mathrm{C}$ for $24 \mathrm{~h}$ (deep red-brown precipitate and clear colorless solution). The reaction vessel was then cooled to room temperature, opened to air and filtered through a fritted funnel and washed with DMF-Acetone-MeOH-DCM then kept under $\mathrm{MeOH}$ for one week prior to gas sorption measurements. The total dry weight of the solid was found to be $64 \mathrm{mg}, 88 \%$ yieldcalculated based on combined weights of the starting materials excluding terminal bromine and hydrogen atoms.

\section{Photolysis}

The photochemical reactions are performed using a $300 \mathrm{~W}$, high-pressure Xe arc lamp. The beam is passed through an infrared filter, a collimating lens, a filter holder equipped with a $415 \mathrm{~nm}$ cutoff filter. Samples are prepared in a $1 \mathrm{~cm}$ path length quartz cubic cuvette, which is placed in a temperature controlled cuvette holder maintained at $20^{\circ} \mathrm{C}$ with a circulated water bath. Samples are prepared by adding $0.8 \mathrm{~mL}$ solution containing photosensitizer $\left[\mathrm{Ru}(\mathrm{bpy})_{3}\right] \mathrm{Cl}_{2}$ and solid polymer, and by saturating with $\mathrm{N}_{2}$ for 10 minutes. After photolysis, $\mathrm{H}_{2}$ measurement is performed by gas chromatography (Shimadzu GC-2014) with a thermal conductivity detector.

\section{ASSOCIATED CONTENT}

\section{Supporting Information.}

Additional experimental details, UV-vis spectra, FT-IR spectra, mass and solid-state NMR spectra, pore size distribution, XPS and EDX analysis, and TGA traces are available. This material is available free of charge via the Internet at http://pubs.acs.org

\section{Author Contributions}

The manuscript was written through contributions of all authors. All authors have given approval to the final version of the manuscript.

\section{Funding Sources}

The authors acknowledge the Egyptian Science and Technology Development Fund (STDF-6125) and Zewail City of Science and Technology Startup fund. We acknowledge financial support from the Paris Sciences et Lettres (PSL) Research University and from Foundation de l'Orangerie for individual Philanthropy and its donors.

\section{References}

1. Witze, A., Energy: That's Oil, Folks. Nature 2007, 445 (7123), 14-17.

2. Lewis, N. S.; Crabtree, G.; Nozik, A. J.; Wasielewski, M. R.; Alivisatos, P.; Kung, H.; Tsao, J.; Chandler, E.; Walukiewicz, W.; Spitler, M.; Ellingson, R.; Overend, R.; Mazer, J.; Gress, M.; Horwitz, J.; Ashton, C.; Herndon, B.; Shapard, L.; Nault, R. M. Basic Research Needs for Solar Energy Utilization. Report of the Basic Energy Sciences Workshop on Solar Energy Utilization, April 18-21, 2005; 2005. United States. doi: $10.2172 / 899136$

3. Lewis, N. S., Powering the Planet. MRS Bulletin 2007, 32 (10), 808-820

4. Crabtree, G. W.; Lewis, N. S., Solar Energy Conversion. Phys. Today 2007, 60 (3), 37-42.

5. Lewis, N. S.; Nocera, D. G., Powering the Planet: Chemical Challenges in Solar Energy Utilization. Proc. Natl. Acad. Sci. 2006, 103 (43), 15729-15735.

6. O'regan, B.; Grätzel, M., A Low-Cost, High-Efficiency Solar Cell Based on Dye-Sensitized Colloidal $\mathrm{TiO}_{2}$ Films. Nature 1991, 353 (6346), 737-740.

7. Grätzel, M., Photoelectrochemical Cells. Nature 2001, 414 (6861), 338-344.

8. Barbe, C. J.; Arendse, F.; Comte, P.; Jirousek, M.; Lenzmann, F.; Shklover, V.; Grätzel, M., Nanocrystalline Titanium Oxide Electrodes for Photovoltaic Applications. $J$. Am. Ceram. Soc. 1997, 80 (12), 3157-3171.

9. Hara, M.; Waraksa, C. C.; Lean, J. T.; Lewis, B. A.; Mallouk, T. E., Photocatalytic Water Oxidation in a Buffered Tris(2, 2'-ipyridyl) Ruthenium Complex-Colloidal $\mathrm{IrO}_{2}$ System. J. Phys. Chem. A 2000, 104 (22), 5275-5280. 
10. Takata, T.; Tanaka, A.; Hara, M.; Kondo, J. N.; Domen, K., Recent Progress of Photocatalysts for Overall Water Splitting. Catal. Today 1998, 44 (1), 17-26.

11. Sun, Q.; Dai, Z.; Meng, X.; Xiao, F.-S., Porous Polymer Catalysts with Hierarchical Structures. Chem. Soc. Rev. 2015, 44 (17), 6018-6034.

12. Zhang, Y.; Ying, J. Y., Main-Chain Organic Frameworks with Advanced Catalytic Functionalities. ACS Catal. 2015, 5 (4), 2681-2691.

13. Wang, X.-S.; Chrzanowski, M.; Yuan, D.; Sweeting, B. S.; Ma, S., Covalent Heme Framework as a Highly Active Heterogeneous Biomimetic Oxidation Catalyst. Chem. Mater. 2014, 26 (4), 1639-1644.

14. Eddaoudi, M.; Moler, D. B.; Li, H.; Chen, B.; Reineke, T. M.; O'keeffe, M.; Yaghi, O. M., Modular Chemistry: Secondary Building Units as a Basis for the Design of Highly Porous and Robust Metal-Organic Carboxylate Frameworks. Acc. Chem. Res. 2001, 34 (4), 319-330.

15. Dawson, R.; Laybourn, A.; Clowes, R.; Khimyak, Y. Z.; Adams, D. J.; Cooper, A. I., Functionalized Conjugated Microporous Polymers. Macromolecules 2009, 42 (22), 8809-8816.

16. Xie, Z.; Wang, C.; deKrafft, K. E.; Lin, W., Highly Stable and Porous Cross-Linked Polymers for Efficient Photocatalysis. J. Am. Chem. Soc. 2011, 133 (7), 2056-2059.

17. Wang, C.; Xie, Z.; deKrafft, K. E.; Lin, W., Light-Harvesting Cross-Linked Polymers for Efficient Heterogeneous Photocatalysis. ACS Appl. Mater. Interfaces 2012, 4 (4), 2288-2294.

18. Kaur, P.; Hupp, J. T.; Nguyen, S. T., Porous Organic Polymers in Catalysis: Opportunities and Challenges. ACS Catal. 2011, 1 (7), 819-835.

19. Cote, A. P.; El-Kaderi, H. M.; Furukawa, H.; Hunt, J. R.; Yaghi, O. M., Reticular Synthesis of Microporous and Mesoporous 2d Covalent Organic Frameworks. J. Am. Chem. Soc. 2007, 129 (43), 12914-12915.

20. Kuhn, P.; Antonietti, M.; Thomas, A., Porous, Covalent Triazine-Based Frameworks Prepared by Ionothermal Synthesis. Angew. Chem. Int. Ed. 2008, 47 (18), 3450-3453.

21. Spitler, E. L.; Dichtel, W. R., Lewis Acid-Catalysed Formation of Two-Dimensional Phthalocyanine Covalent Organic Frameworks. Nature Chem. 2010, 2 (8), 672-677.

22. Wu, D.; Xu, F.; Sun, B.; Fu, R.; He, H.; Matyjaszewski, K., Design and Preparation of Porous Polymers. Chem. Rev. 2012, 112 (7), 3959-4015.

23. Aratani, N.; Kim, D.; Osuka, A., Discrete Cyclic Porphyrin Arrays as Artificial Light-Harvesting Antenna. Acc. Chem. Res. 2009, 42 (12), 1922-1934.

24. Gust, D.; Moore, T. A.; Moore, A. L., Solar Fuels Via Artificial Photosynthesis. Acc. Chem. Res. 2009, 42 (12), 1890-1898.

25. So, M. C.; Wiederrecht, G. P.; Mondloch, J. E.; Hupp, J. T.; Farha, O. K., Metal-Organic Framework Materials for LightHarvesting and Energy Transfer. Chem. Commun. 2015, 51 (17), 3501-3510.

26. Balzani, V.; Bergamini, G.; Ceroni, P.; Vögtle, F., Electronic Spectroscopy of Metal Complexes with Dendritic Ligands. Coord. Chem. Rev. 2007, 251 (3-4), 525-535.

27. Alkordi, M. H.; Liu, Y.; Larsen, R. W.; Eubank, J. F.; Eddaoudi, M., Zeolite-Like Metal-Organic Frameworks as Platforms for Applications: On Metalloporphyrin-Based Catalysts. J. Am. Chem. Soc. 2008, 130 (38), 12639-12641.

28. Wang, J.-L.; Wang, C.; Lin, W., Metal-Organic Frameworks for Light Harvesting and Photocatalysis. ACS Catal. 2012, 2 (12), 2630-2640.

29. Kent, C. A.; Liu, D.; Ma, L.; Papanikolas, J. M.; Meyer, T. J.; Lin, W., Light Harvesting in Microscale Metal-Organic
Frameworks by Energy Migration and Interfacial Electron Transfer Quenching. J. Am. Chem. Soc. 2011, 133 (33), 12940-12943.

30. Kent, C. A.; Mehl, B. P.; Ma, L.; Papanikolas, J. M.; Meyer, T. J.; Lin, W., Energy Transfer Dynamics in Metal-Organic Frameworks. J. Am. Chem. Soc. 2010, 132 (37), 1276712769.

31. Durham, B.; Caspar, J. V.; Nagle, J. K.; Meyer, T. J., Photochemistry of Tris(2, 2'-bipyridine) Ruthenium (2+) Ion. J. Am. Chem. Soc. 1982, 104 (18), 4803-4810.

32. Artero, V.; Chavarot-Kerlidou, M.; Fontecave, M., Splitting Water with Cobalt. Angew. Chem. Int. Ed. 2011, 50 (32), 7238-7266

33. Jiang, J. X.; Su, F.; Trewin, A.; Wood, C. D.; Campbell, N. L.; Niu, H.; Dickinson, C.; Ganin, A. Y.; Rosseinsky, M. J.; Khimyak, Y. Z., Conjugated Microporous Poly (Aryleneethynylene) Networks. Angew. Chem. Int. Ed. 2007, $46(45), 8574-8578$.

34. Jiang, J.-X.; Su, F.; Trewin, A.; Wood, C. D.; Niu, H.; Jones, J. T.; Khimyak, Y. Z.; Cooper, A. I., Synthetic Control of the Pore Dimension and Surface Area in Conjugated Microporous Polymer and Copolymer Networks. J. Am. Chem. Soc. 2008, 130 (24), 7710-7720.

35. Dawson, R.; Cooper, A. I.; Adams, D. J., Nanoporous Organic Polymer Networks. Progress in Polymer Science 2012, 37 (4), 530-563.

36. Iupac Commission on Colloid and Surface Chemistry Including Catalysis. Pure Appl. Chem. 1985, 57 (4), 603619.

37. Wood, C. D.; Tan, B.; Trewin, A.; Su, F.; Rosseinsky, M. J.; Bradshaw, D.; Sun, Y.; Zhou, L.; Cooper, A. I., Microporous Organic Polymers for Methane Storage. Advanced Materials 2008, 20 (10), 1916-1921.

38. Nazeeruddin, M. K.; Kay, A.; Rodicio, I.; Humphry-Baker, R.; Müller, E.; Liska, P.; Vlachopoulos, N.; Grätzel, M., Conversion of Light to Electricity by cis- $\mathrm{X}_{2}$ bis(2, 2'bipyridyl-4, 4'-dicarboxylate)ruthenium (II) Charge-Transfer Sensitizers (X= Cl-, Br-, I-, $\mathrm{CN}-$, and $\mathrm{SCN}-)$ on Nanocrystalline Titanium Dioxide Electrodes. J. Am. Chem. Soc. 1993, 115 (14), 6382-6390.

39. Pazderski, L.; Pawlak, T.; Sitkowski, J.; Kozerski, L.; Szłyk, E., 1H NMR Assignment Corrections and 1H, 13C, 15N NMR Coordination Shifts Structural Correlations in Fe (II), $\mathrm{Ru}$ (II) and Os (II) Cationic Complexes with 2, 2'-bipyridine and 1,10-phenanthroline. Magn. Reson. Chem. 2010, 48 (6), 450-457.

40. Omberg, K. M.; Schoonover, J. R.; Treadway, J. A.; Leasure, R. M.; Dyer, R. B.; Meyer, T. J., Mid-Infrared Spectrum of [Ru (Bpy) 3] 2+*. J. Am. Chem. Soc. 1997, 119 (30), 70137018.

41. Mohammed, O. F.; Xiao, D.; Batista, V. S.; Nibbering, E. T. J. Excited-State Intramolecular Hydrogen Transfer (ESIHT) of 1,8-dihydroxy-9,10-anthraquinone (DHAQ) Characterized by Ultrafast Electronic and Vibrational Spectroscopy and Computational Modeling. J. Phys. Chem. A 2014,118, 30903099

42. Sun, J.; Yu, W.; Usman, A.; Isimjan, T. T.; DGobbo, S.; Alarousu, E.; Takanabe, K.; Mohammed, O. F., Generation of Multiple Excitons in $\mathrm{Ag}_{2} \mathrm{~S}$ Quantum Dots: Single HighEnergy Versus Multiple-Photon Excitation. J. Phys. Chem. Lett. 2014, 5 (4), 659-665.

43. Kallioinen, J.; Benkö, G.; Sundström, V.; Korppi-Tommola, J. E.; Yartsev, A. P., Electron Transfer from the Singlet and Triplet Excited States of $\mathrm{Ru}$ (dcbpy) ${ }_{2} \quad(\mathrm{NCS})_{2}$ into Nanocrystalline $\mathrm{TiO}_{2}$ Thin Films. J. Phys. Chem. B 2002, 106 (17), 4396-4404. 
44. Wang, J.-L.; Wang, C.; deKrafft, K. E.; Lin, W., CrossLinked Polymers with Exceptionally High Ru(bipy) ${ }_{3}{ }^{2+}$ Loadings for Efficient Heterogeneous Photocatalysis. ACS Catal. 2012, 2 (3), 417-424.

45. Reynal, A.; Pastor, E.; Gross, M. A.; Selim, S.; Reisner, E.; Durrant, J. R., Unravelling the PH-dependence of a Molecular Photocatalytic System for Hydrogen Production. Chem. Sci. 2015, 6 (8), 4855-4859.

46. Dong, X.-Y.; Zhang, M.; Pei, R.-B.; Wang, Q.; Wei, D.-H.; Zang, S.-Q.; Fan, Y.-T.; Mak, T. C. W., A Crystalline Copper(II) Coordination Polymer for the Efficient VisibleLight-Driven Generation of Hydrogen. Angew. Chem. Int. Ed. 2016, 55 (6), 2073-2077.

47. Pullen, S.; Fei, H.; Orthaber, A.; Cohen, S. M.; Ott, S., Enhanced Photochemical Hydrogen Production by a Molecular Diiron Catalyst Incorporated into a MetalOrganic Framework. J. Am. Chem. Soc. 2013, 135 (45), 16997-17003.

48. Sasan, K.; Lin, Q.; Mao, C.; Feng, P., Incorporation of Iron Hydrogenase Active Sites into a Highly Stable MetalOrganic Framework for Photocatalytic Hydrogen Generation. Chem. Commun. 2014, 50 (72), 10390-10393.

49. Bhattacharjee, A.; Chavarot-Kerlidou, M.; Andreiadis, E. S.; Fontecave, M.; Field, M. J.; Artero, V., Combined Experimental-Theoretical Characterization of the HydridoCobaloxime [ $\mathrm{HCo}(\mathrm{dmgH}) 2(\mathrm{PnBu} 3)]$. Inorg. Chem. 2012, 51 (13), 7087-7093.

50. Bartelmess, J.; Francis, A. J.; El Roz, K. A.; Castellano, F. N.; Weare, W. W.; Sommer, R. D., Light-Driven Hydrogen Evolution by BODIPY-Sensitized Cobaloxime Catalysts. Inorg. Chem. 2014, 53 (9), 4527-4534.

51. Panagiotopoulos, A.; Ladomenou, K.; Sun, D.; Artero, V.; Coutsolelos, A. G., Photochemical Hydrogen Production and Cobaloximes: The Influence of the Cobalt Axial N-Ligand on the System Stability. Dalton Trans. 2016, 45 (15), 67326738 .

52. Sprick, R. S.; Bonillo, B.; Clowes, R.; Guiglion, P.; Brownbill, N. J.; Slater, B. J.; Blanc, F.; Zwijnenburg, M. A.; Adams, D. J.; Cooper, A. I., Visible Light Driven Hydrogen Evolution Using Planarized Conjugated Polymer Photocatalysts. Angew. Chem. Int. Ed. 2016, 55 (5), 1792 1796. 
TOC

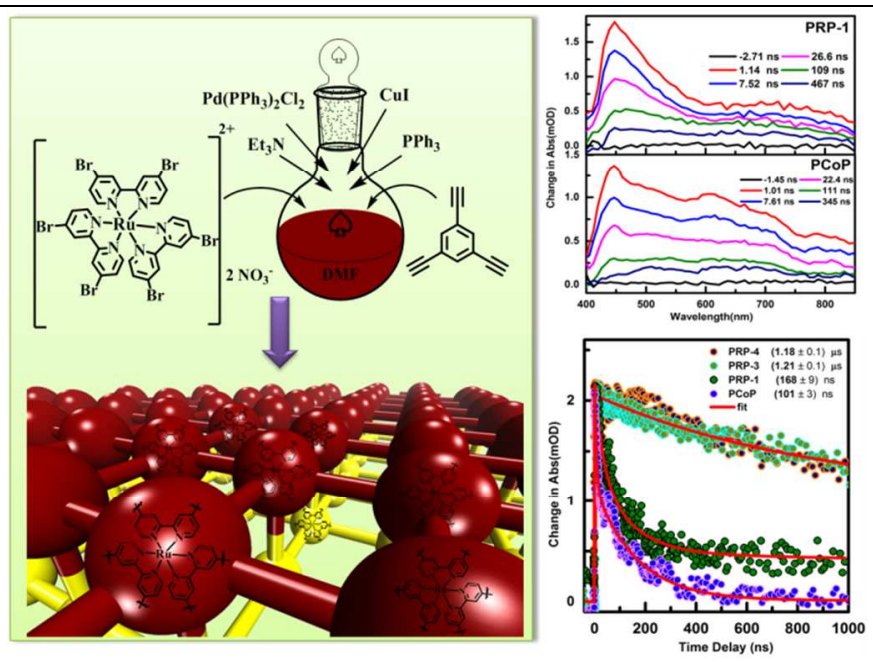

27 